\title{
Pemanfaatan Penggunaan Aplikasi E-Learning Dalam Pembelajaran Daring Pada IAKN Tarutung
}

\author{
${ }^{1)}$ Desilia Selvida, ${ }^{2)}$ Malinda Sari Sembiring \\ 1)Ilmu Komputer, Fakultas Ilmu Komputer \& Teknologi Informasi, Universitas \\ Sumatera Utara, Indonesia \\ ${ }^{2)}$ Akuntansi, Fakultas Ekonomi \& Bisnis, Universitas Sumatera Utara, Indonesia
}

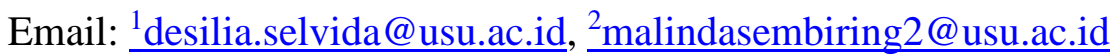

\begin{tabular}{|c|c|}
\hline INFORMASI ARTIKEL & ABSTRAK \\
\hline \multirow[t]{2}{*}{$\begin{array}{l}\text { Kata Kunci: } \\
\text { Website } \\
\text { Aplikasi } \\
\text { E-Learning } \\
\text { Daring }\end{array}$} & $\begin{array}{l}\text { Pengabdian ini dilakukan untuk sebagai media pembelajaran antara Dosen } \\
\text { dan Mahasiswa sehingga bertujuan mendeskripsikan standar mutu } \\
\text { pelaksanaan e-learning sebagai media pembelajaran yang efektif, } \\
\text { mengidentifikasi keefektifan perencanaan pembelajaran elearning, } \\
\text { mengidentifikasi keefektifan perancangan dan pembuatan materi } \\
\text { pembelajaran elearning, mengidentifikasi keefektifan metode penyampaian } \\
\text { pembelajaran e-learning, mengidentifikasi keefektifan pelaksanaan dan } \\
\text { interaktivitas pembelajaran e-learning, mengidentifikasi keefektifan evaluasi } \\
\text { pelaksanaan e-learning, mengetahui faktor penghambat dan pendukung } \\
\text { pelaksanaan e-learning sebagai media pembelajaran. Perancangan aplikasi } \\
\text { ini dikemas dengan icon-icon e-learning dengan bahasa yang sederhana dan } \\
\text { komunikatif. }\end{array}$ \\
\hline & $A B S T R A C T$ \\
\hline $\begin{array}{l}\text { Keywords: } \\
\text { Website } \\
\text { Application } \\
\text { E-Learning } \\
\text { Daring }\end{array}$ & $\begin{array}{l}\text { This service is carried out as a learning medium between } \\
\text { lecturers and students so that it aims to describe the } \\
\text { quality standards of the implementation of e-learning as an } \\
\text { effective learning medium, identify the effectiveness of e- } \\
\text { learning learning planning, identify the effectiveness of the } \\
\text { design and manufacture of e-learning learning materials, } \\
\text { identify the effectiveness of e-learning delivery methods, } \\
\text { identify the effectiveness of the implementation and } \\
\text { interactivity of e-learning learning, identify the } \\
\text { effectiveness of evaluating the implementation of e- } \\
\text { learning, determine the inhibiting and supporting factors } \\
\text { for the implementation of e-learning as a learning medium. } \\
\text { The design of this application is packed with e-learning } \\
\text { icons in simple and communicative language. }\end{array}$ \\
\hline
\end{tabular}




\section{PENDAhULUAN}

Penerapan suatu model pembelajaran memiliki satu komponen yang perlu diperhatikan agar suatu model pembelajaran dapat berkesinambungan dan memberikan pengaruh dalam pelaksanaannya. Komponen tersebut yaitu desain, aplikasi/implementasi, dan manajemen atau maintenance. Berkaitan dengan pembelajaran, pemanfaatan teknologi informasi dalam hal ini e-learning diperlukan tidak hanya pendidik yang terampil memanfaatkan teknologi serta teknologi untuk pembuatan bahan ajar, akan tetapi diperlukan suatu rancangan agar dapat melaksanakan pembelajaran dengan efektif. Dalam sebuah rancangan pembelajaran (desain instruksional) terdapat suatu proses untuk memandu pelaku (aktor) untuk mendesain, mengembangkan, menerapkan konten e-learning dengan memanfaatkan infrastruktur dan aplikasi elearning yang tersedia. Pada tahap selanjutnya dalam implementasi e-learning terdapat tahap evaluasi yang dimanfaatkan untuk merevisi atau penyesuaian terhadap tahaptahap sebelumnya. Desain instruksional merupakan proses dinamis yang dapat berubah-ubah sesuai dengan informasi dan evaluasi yang diterima bertujuan untuk meningkatkan hasil pembelajaran peserta didik sehingga tujuan pembelajaran dapat tercapai.

Dani Azhar, 2019. Dalam merancang aplikasi e-learning siswa berbasis web ini, penulis menggunakan metode wawancara sebagai bahan acuan perancangan sistem. Hasil dari penelitian ini adalah aplikasi e-learning siswa yang dapat mengakomodasi masalah pemberian materi pelajaran, pengerjaan tugas yang tidak harus selalu di kelas dan melakukan kuis online

Pengabdian ini membahas mengenai masalah proses pembelajaran daring dengan keadaan di era digitalisasi sehingga bertujuan akan tercapai untuk mendapat hasil belajar secara optimal. Pengabdian ini dilakukan dengan pendekatan deskriptif kualitatif dalam menganalisis datanya yang menekankan pada makna, penalaran dan melihat pada situasi tertentu serta menggambarkan pola tingkah perilaku objek yang sedang diteliti. Dari hasil pengapatan langsung dengan melakukan observasi secara langsung dapat diambil sebuah kesimpulan bahwa diperlukan suatu media aplikasi pembelajaran daring yang dapat meningkatkan proses belajar mengajar. Aplikasi memiliki peranan yang sangat penting dalam menunjang tercapainya tujuan pembelajaran mahasiswa/I.

\section{MASALAH}

Dari hasil wawancara dengan Dosen dan interaksi singkat percakapan yang telah dilakukan pada Mahasiswa. Dari hasil pengamatan langsung dapat diambil sebuah kesimpulan bahwa sebagian dosen menyatakan bahwa pembelajaran daring berjalan kurang efektif dikarenakan dosen sebagai pengampu mata kuliah idak benar-benar dapat "hadir" secara langsung untuk melakukan proses transfer pengetahuan dan sekaligus penilaian terhadap mahasiswa yang mengikuti mata kuliah yang bersangkutan. Oleh karena itu dibutuhkan suatu apilkasi yang mampu menjadi media yang bisa memfasilitasi Dosen dan Mahasiswa dapat belajar seakan berada di ruangan. Pembelajaran yang efektif dapat dikatakan pembelajaran yang memanfaatkan teknologi informasi dan komunikasi secara optimal dalam proses pembelajarannya sebagai alat bantu. Salah satu pemanfaatan teknologi informasi dan komunikasi dalam pembelajaran adalah dengan memanfaatkan elearning. Dengan adanya sosialisasi ini diharapkan dapat menumbuhkan semangat belajar mahasiswa dalam mengharapkan cita-cita mereka. 


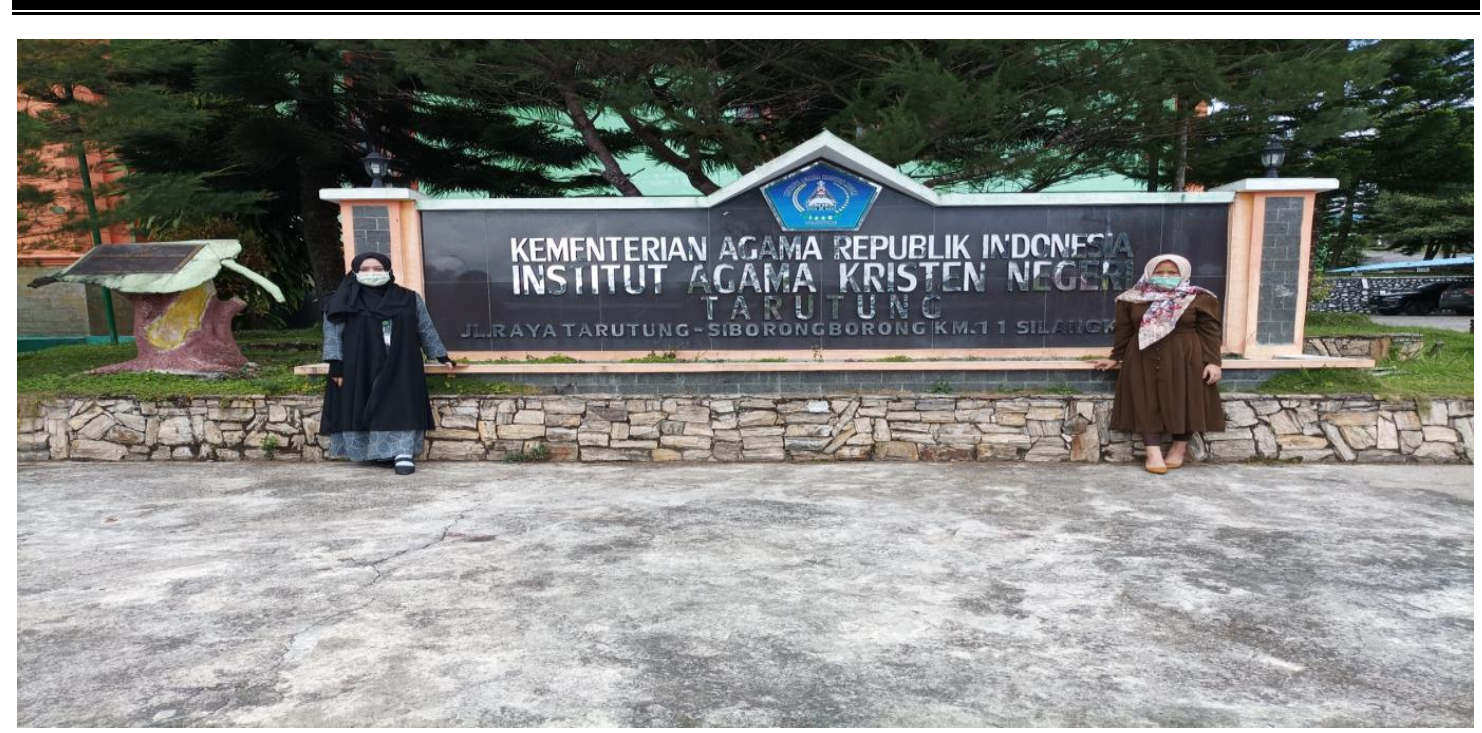

Gambar 1. Lokasi Pengabdian Kepada Masyarakat

\section{METODE}

Untuk membantu tim dalam mencapai tujuan kegiatan ini maka dilakukan pendekatan kepada instansi yang terkait yaitu IAKN Tarutung. Selain itu Tim juga memanfaatkan ruangan aula yang akan digunakan sebagai LAB tempat pelatihan kepada Dosen dann Mahasiswa di IAKN Tarutung. Adapun meode yang digunakan meliputi:

1. Tatap Muka

Tatap muka adalah metode yang digunakan untuk melakukan sosialisasi terhadap Dosen dengan bertemu dan bertatap muka secara langsung dan berada di tempat yang sama.

2. Menjelaskan secara Langsung

Menjelaskan secara langsung juga merupakan metode yang digunakan dalam penyampaian bagaimana menjelaskan kepada Dosen mengenai aplikasi E-Learning untuk proses belajar mengajar terhadap Mahasiswa/i.

\section{HASIL DAN PEMBAHASAN}

Pelaksanaan kegiatan sosialisasi penggunaan aplikasi E-Learning sebagai media pembelajaran mahasiswa/I IAKN Tarutung, dilakukan denga metode tatap muka sesuai pada bulan Agustus sesuai dengan protokol arahan pemerintah. Kegiatan sosialisasi dimudahkan dengan adanya aula yang besar sebagai LAB Komputer pada IAKN Tarutung. Untuk menjelaskan kepada Dosen, Staff admin, Mahasiswa tentang penggunaan aplikasi ini, ketua tim pelaksana menjelaskan dengan bantuan laptopnya sendiri, kemudian ditampilkan ke layer white board menggunakan proyektor agar bisa dilihat dengan mudah oleh semua guru pada saat proses sosialisasi berlangsung. Saat kegiatan sosialisasi berlangsung, untuk memudahkan para Dosen langsung mennggunakan aplikasi E-Learning, maka aplikasi sudah kami install di CPanel Hosting IAKN Tarutung. Sehingga Dosen dapat menguji coba baik menggunakan PC Komputer, Laptop, dan HP masing-masing.

Pada tahapan tim sepakat Menyusun materi untuk kegiatan sosialisasi menggunakan slide persentasi dengan bantuan Ms. Office Power Point, yang dijelaskan secara rinci dan sederhana sesuai dengan kebutuhan peserta kegiatan sosialisasi. Materi kegiatan sosialisasi penggunaan aplikasi E-Learning sebagai media pembelajaran mahasiswa/I IAKN Tarutung ini difokuskan agar benar-benar memberikan penyegaran dan penambahan wawasan bagi guru maupun siswa disekolah nantinya. 
Pada saat pelaksanaan kegiatan, situasi dan kondisi kegiatan sosialisasi penggunaan aplikasi E-Learning sebagai media pembelajaran mahasiswa/I IAKN Tarutung sangatlah kondusif dan memberikan kenyamanan bagi para peserta. Karena pelaksana teknis kegiatan dilakukan di AULA sehingga bisa focus melaksanakan kegiatan dengan nyaman.

Pada tahap akhir pelaksanaan kegiatan sosialisasi penggunaan aplikasi E-Learning sebagai media pembelajaran mahasiswa/I IAKN Tarutung, Sebagian Dosen awalnya mengalami kesulitan dalam mengoperasikan computer. Dikarenakan mayoritas Dosen IAKN Tarutung ialah lanjut usia. Tapi setelah diarahkan dan dipraktekan dengan seksama para Dosen bisa menggunakannya dengan baik. Hal tersebut kami simpulkan dengan mengambil sebuah tolak ukur dari hasil post-test penggunaan computer saat kegiatan berlangsung, yang mana menunjukkan kemajuan dan hasil yang positif berbeda dari sebelum dilaksakanannya kegiatan sosialisasi ini.

Seusai acara kami tim pengabdian program kemitraan masyarakat melaksanakan rapat rumusan akhir bersama untuk Menyusun draft awal laporan akhir pengabdian program kemitraan masyarakat sekaligus berpamitan dan bertrimakasih Kembali atas Kerjasama serta kesempatan yang diberikan kepada kami. Adapun berikut merupakan ruang lingkup IAKN Tarutung.

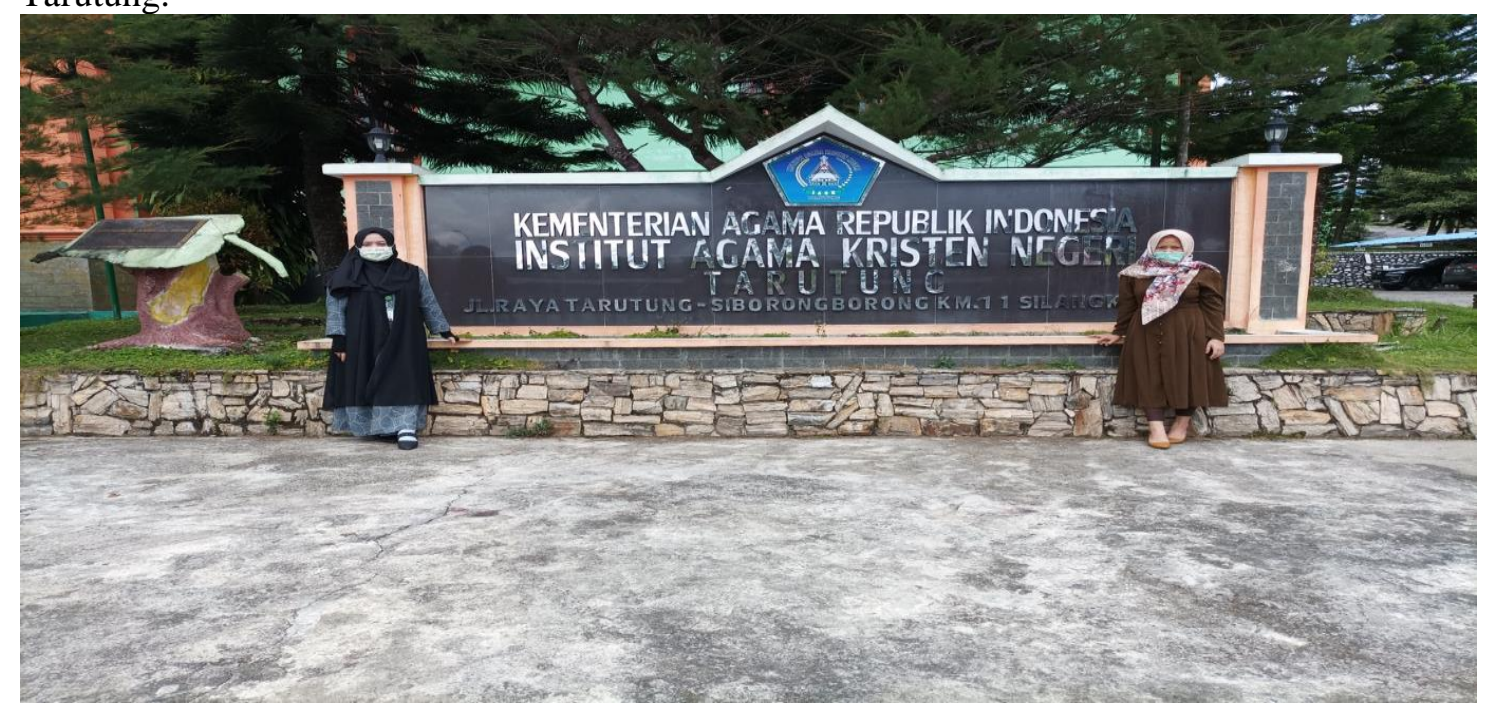

Gambar 2. Lingkungan IAKN Tarutung

Adapun berikut merupakan halaman utama tampilan menu login bagi peserta pelatihan, dimana peserta akan mendapatkan pelatihan penggunaan aplikasi. 


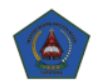

Gambar 3. Halaman Login Website

\section{KESIMPULAN}

Dari hasil pengabdian kemitraan masyarakat mandiri, dengan judul sosialisasi penggunaan aplikasi E-Learning sebagai media pembelajaran mahasiswa/I IAKN Tarutung, dapat diambil kesimpulan bahwa:

1. Sosialisasi penggunaan aplikasi E-Learning sebagai media pembelajaran mahasiswa/I IAKN Tarutung ini dikatakan cukup berhasil, dimana mendapat respon yang positif dari para Dosen.

2. Sebagian Dosen telah memahami konsep dan teknik penggunaan aplikasi, yang nantinya bisa di implementasi kan kepada mahasiswa/i.

3. Secara kesuluruhan diharapkan dengan dilakukan sosialisasi ini, dapat meningkatkan sistem belajar mengajar di kalangan IAKN Tarutung mulai perlahan menggunakan teknologi untuk mendapatkan hasil yang lebih efisien.

\section{DAFTAR PUSTAKA}

Al Fatta Hanif. (2007). Analisis dan Perancangan Sistem Informasi untuk keunggulan bersaing Perusahaan dan Organisasi Modern. Yogyakarta, CV Andi Offset.

Andalia F., Setiawan Budi Eko. (2015). Pengembangan Sistem Informasi Pengolahan Data Pencari Kerja Pada Dinas Sosial dan Tenaga Kerja Kota Padang. Jurnal Ilmiah Komputer dan Informatika, 4 (2), 93-98. Diakses dari: https://ojs.unikom.ac.id/index.php

Arif Setyawan, Joko Wandyatmono. Jurnal: "Sistem Informasi Penggajian Pegawai Kecamatan Geneng Kabupaten Ngawi”, Journal Speed - Sentra Penelitian Engineering dan Edukasi - Volume 1 No 3 - 2009 - ijns.org. Universitas Surakarta.

Asmara, Rini. (2016). Sistem Informasi Pengolahan Data Penanggulangan Bencana Pada Kantor Badan Penanggulangan Bencana Daerah (BPBD) Kabupaten Padang 
Pariaman. Jurnal J- Click, 3 (2), 80-91. Diakses dari http://ejurnal.jayanusa.ac.id/index.php/J- Click/article/view/28

Azhar, Dani. (2019). Aplikasi E-Learning Siswa Berbasis Web Pada SMPN Bernas Kabupaten Pelalawan Riau (Studi Kasus SMPN Bernas Kab.Pelalawan Riau). Diakses dari:http://eprints.uty.ac.id/id/eprint/2693.

Bekti, Bintu Humairah. (2015). Mahir Membuat Website dengan Adobe Dreamweaver CS6, CSSdan Jquery. Yogyakarta, Andi.

Numiek, Sulistyo Hanum. (2013). Kefektifan E-Learning Sebagai Media Pembelajaran (Studi Evaluasi Model Pembelajaran E-Learning SMK Telkom Sandhy Putra Purwokerto). Jurnal Pendidikan Vokasi, Vol 3, Nomor1, Februari 2013. 